\title{
Efficient modified concrete for irrigation and drainage facilities construction
}

\author{
Evgeniya Tkach* $^{*}$ and Yuliya Sadchikova \\ Moscow State University of Civil Engineering, Yaroslavskoe shosse, 26, Moscow, 129337, Russia
}

\begin{abstract}
The paper describes scientific and technical prerequisites for the development of composition of and production method for hydrophobic complex modifier based on the industrial wastes, including technical lignosulfonates (TLS) as a plasticizing ingredient; oil and fat tar as hydrophobic ingredient; and saponified wood pitch (SWP) as air entraining ingredient. The purpose of the presented studies was the development of an efficient modified concrete composition for construction of irrigation and drainage facilities construction by using a complex hydrophobic modifier. Experimental studies were carried out on concrete samples made of reference and test compositions in the laboratory of the "Building Materials" Department of the National Research Moscow State University of Civil Engineering. Comprehensive studies showed that the use of hydrophobic modifier allows obtaining concrete with water bleeding ratio reduced by $35-40 \%$; reducing the concrete capillary suction and water absorption by 3 times; and increasing water penetration pressure (W8 and more), in comparison with concrete without additives. The developed complex hydrophobic modifier increases the strength by $12-18 \%$ and reduces shrinkage strain of concrete by $7.5 \%$ in comparison with the control composition without the modifier.
\end{abstract}

\section{Introduction}

The efficiency of using reclaimed land is inextricably linked with durability and operational reliability of an extensive system of commissioned hydraulic engineering structures. The State Program for the Land Reclamation Development provides for the restoration of irrigation facilities on an area of 50 thousand hectares by 2020, including about 13 thousand hectares of irrigated land in the territory of the Crimean Peninsula. High requirements are imposed on concrete used in hydrotechnical construction in terms of durability, which is primarily assessed by the concrete frost and water resistance. The modern variety and complexity of technical problems pose new tasks for the improvement of building materials applied in various fields. One solution to these problems is creating and using new complex additives for concrete mixtures and mortars, rationally combining the necessary process and operational characteristics. The level of modern construction, the quality, efficiency, and

\footnotetext{
* Corresponding author: ev_tkach@mail.ru
} 
competitiveness of various construction facilities are provided, first of all, due to the use of modified concrete and reinforced concrete. Such modifiers, introduced in small amounts, significantly affect the physical and mechanical processes of the concrete structure formation, form a favorable structure allowing to significantly improve the complex of its physical and technical properties and to increase its durability [1-4]. As practice shows, the key point in solving these problems is the use of hydrophobic modifiers.

\section{Problem statement}

The accumulated practical experience, as well as theoretical issues of improving the engineering and operational properties of hydraulic concrete have been described in various scientific papers [5-8]. In the irrigation and drainage structures, non-massive concrete grades are used, that do not require adjusting the exotherm values. Features of concrete grades used for irrigation and drainage structures, in comparison with other types (for industrial and civil, road, and hydraulic engineering construction) are related to the specific conditions of their operation. In irrigation and drainage facilities construction, thin-walled structures are mainly used (with a concrete thickness of 5-15 cm), which are subjected to more severe impact than other structures in the same natural environment. Multifactorial aggressiveness conditions of the environment are expressed in sharp temperature and humidity fluctuations, a high degree of mineralization of the transported water, the corrosive activity of groundwater, the cavitation effect of water flow, and other factors. All of the above complex in various combinations constantly affect the reinforced concrete of such structures, causing their damage, and reduce the operational reliability of irrigation and drainage facilities. In addition, there is an increasing number of damages and failures of structures. At the same time, as noted in the technical literature, a significant amount of irrigation water is lost during transportation. Recently, various anti-filtration channel lining designs have found wide application in the irrigation and drainage facilities construction: such as concrete film lining in the cast-in-place version and precast concrete film lining; however, the average filtration losses in the channels with the said lining are still within the range of $15-20 \%$ [7, 8]. A significant drawback of these film screens $(0.2 \mathrm{~mm}$ thick $)$ is their high damage rate due to mechanical impacts during construction and operation.

A promising route is the development and implementation of effective measures to reinforce and protect reinforced concrete with materials featuring a high degree of resistance to aggressive environmental factors, for example, polymer compositions. Polymer-concrete production methods were explored for industrial and civil construction [3, 4]. However, in the practice of modern irrigation and drainage facilities construction, polymer concrete is not widely spread, because of its scarcity and high cost; therefore, concrete and reinforced concrete remain the main building materials for irrigation and drainage facilities. In this connection, solving the problems of obtaining high-performance concrete, including for irrigation and drainage construction, by modification with complex hydrophobic additives, especially on the basis of local raw materials, is becoming increasingly relevant.

\section{Materials and Methods}

Portland cement CEM I 32,5N (GOST 31108-2016 "Standard cements. Technical conditions") of the Mikhailovsky Cement Plant of ZAO "Mikhailovcement" was used for modified concrete. Tests of cement were performed in accordance with GOST 30744-2001 "Cement. Test methods using multifractional sand". The sand of the Eganovskoye quarry from the territory of the Ramensky district of the Moscow region was used as a fine aggregate. Crushed stone from the Ivanovo region OAO "Hromtsovskii quarry" was used as the coarse aggregate. Properties of sand were determined by the methods of GOST 8735-88 "Sand for construction works. Methods of testing." Properties of crushed stone were determined by the methods of GOST 8269.0-97 "Crushed stone and gravel from dense rocks and 
production waste for construction works. Methods of physical and chemical testing". The results of the tests showed that the aggregates for the content of clay, pulverized and organic impurities, granulometric composition correspond to the standard requirements of GOST 8376-2014 "Sand for construction works. Technical conditions" and GOST 8267-93 "Crushed stone and gravel from hard rocks for construction works. Technical conditions". Drinking tap water, as well as any water having a $\mathrm{pH}$ at least 4 and corresponding the requirements of GOST 23732-2011 "Water for concretes and mortars. Technical conditions", was used for mixing concrete ingredients. Water did not contain any impurities that violated the setting and hardening of cement paste and concrete as well as impurities that reduced the strength and frost resistance of concrete: sulfates no more than $2700 \mathrm{mg} / \mathrm{l}$ (in terms of $\left.\mathrm{S}_{04}\right)$ and all salts not more than $5000 \mathrm{mg} / \mathrm{l}$.

For the preparation of hydrophobic complex modifiers the following components were used:

Technical lignosulfonates (LST) of the plant of the OAO "Maloyaroslavetskii Lespromkhoz" of the Kaluga region are used as a plasticizing agent. LST are the products of waste processing of the pulp and paper industry and meet requirements TU 13-0281036029-94.

Fatty tar from the Moscow oil refinery was used as a hydrophobic component in the composition of modifier. MNPZ is the oil refinery of "Gazprom Neft", located in Moscow in the Kapotnya district.

To accelerate the hardening of cement in the modifier included triethanolamine, manufactured by OOO TD "LOGOS", which meets the requirements of GOST 244-76 "Sodium thiosulfate crystalline. Technical conditions".

As the air-entraining agent was used saponified wood resin (SWR). The most valuable components of resin are used for the production of SWR. These components are obtained in the process of pyrolysis of wood undergoing alkalization.

The composition of the developed hydrophobic modifier GST in the form of an oil-inwater emulsion of fatty tar in an aqueous solution of LST is presented in Table 1.

Table 1. Composition GST hydrophobic modifier in the form of oil-in-water emulsion

\begin{tabular}{|l|c|}
\hline \multicolumn{1}{|c|}{ Components } & Content of components, mass \% \\
\hline Fatty tar & 0,6 \\
\hline Technical lignosulfonates (LST) & 1,2 \\
\hline Triethanolamine & 3,5 \\
\hline Saponified wood resin (SWR) & 0,2 \\
\hline Water & The rest is up to $100 \%$ \\
\hline
\end{tabular}

The selection of concrete compositions was carried out taking into account the requirements of GOST 27006-86 "Concretes. Rules for the selection of the composition" and by optimizing it using the method of mathematical planning of the experiment.

For testing the obtained modified concrete standard methods were used according to GOST 10181-2014 "Concrete mixes. Test methods", GOST 10180-2012 Concretes. Methods for determining the strength of the control samples", GOST 10060-2012 "Concretes. 
An accelerated method for determining frost resistance", GOST 12730.5-84 (2002)" Concretes. Methods for determining water resistance".

The reliability of the results obtained is confirmed by the application of generally accepted and standard research methods and by statistical processing of the obtained data ensuring sufficient accuracy with a probability of at least $95 \%$.

\section{Results}

Complex studies on the effect of the complex hydrophobic modifier on the properties of cement and concrete mixtures, hardened concrete were conducted in this work. Known organomineral additive of GPD was used in the study [7] for comparative analysis. The test results for the determination of the normal density and setting time are presented in Table 2.

Table 2. Normal density and setting time of Mikhailovskii Portland cement with hydrophobized modifiers

\begin{tabular}{|c|c|c|c|c|c|c|c|}
\hline \multirow{2}{*}{$\begin{array}{c}\text { Additive, } \\
\% \text { by } \\
\text { weight of } \\
\text { binder }\end{array}$} & \multicolumn{4}{|c|}{ Mineral composition of clinker } & \multirow{2}{*}{$\begin{array}{c}\text { Standard } \\
\text { consistency, } \\
\%\end{array}$} & \multicolumn{2}{|c|}{ Initial set, minutes } \\
\hline & $\mathrm{C} 3 \mathrm{~S}$ & $\mathrm{C} 2 \mathrm{~S}$ & $\mathrm{C} 3 \mathrm{~A}$ & $\mathrm{C} 4 \mathrm{AF}$ & & beginning & ending \\
\hline $\begin{array}{l}\text { Without } \\
\text { additive }\end{array}$ & \multirow{3}{*}{47,92} & \multirow{3}{*}{19,09} & \multirow{3}{*}{8,65} & \multirow{3}{*}{13,6} & 26,7 & 165 & 480 \\
\hline $\begin{array}{l}\text { GPD } \\
0,6 \% \\
\end{array}$ & & & & & 24,0 & 185 & 440 \\
\hline $\begin{array}{c}\text { GST } \\
0,6 \% \\
\end{array}$ & & & & & 23,0 & 170 & 405 \\
\hline
\end{tabular}

It should be noted that with an increase of the modifier in the cement-water paste composition, its normal density initially decreases sharply and then stabilizes. Further additives' increasing practically doesn't affect the change in the studied characteristics of the cementwater paste. Offered hydrophobic additive in an optimum amount shortens setting time of the cement-water paste with a basic composition (without additive), due to the hardening accelerator TSN included in its composition. The increase of admixtures content above the optimum, apparently, helps to reduce the thickness of the solvation shells on the surface of the cement particles, which further increases the volume of free water and quickly reduces the molecular forces of interaction between adjacent particles [7]. In this case, the water retention capacity of the dispersed phase (cement) decreases, which leads to water bleeding. At the same time, the amount of free water in the cement-water system per unit of volume is minimized. Solid particles approach each other as much as possible and the rheological properties of the system deteriorate due to the mechanical coupling between particles.

The results of studies of water separation concrete mixes are presented in Table 3.

Table 3. Water bleeding

\begin{tabular}{|c|c|c|}
\hline $\begin{array}{c}\text { Modifier, \% by weight of } \\
\text { binder }\end{array}$ & Water-cement ratio & Water bleeding, \% \\
\hline Without additive & 0,45 & 0,6 \\
\hline GPD 0,6\% & 0,45 & 0,4 \\
\hline GST 0,6 \% & 0,45 & 0,24 \\
\hline
\end{tabular}

It is found that application of a hydrophobic complex modifier of the GST type makes it possible to obtain concrete mixtures with reduced water bleeding by $35-40 \%$, to reduce the 
water absorption of concrete by 3 times, to increase water resistance (W8 and more) in comparison with concrete without additives. The kinetics of water absorption of concrete is presented in Figure 1.

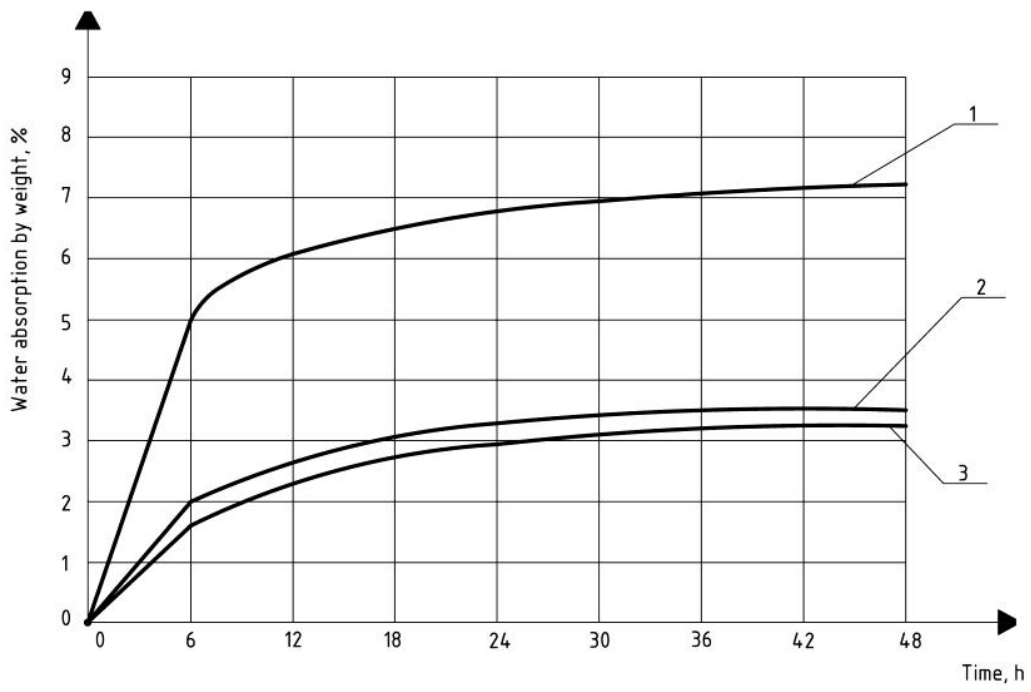

1 - composition without modifier ; with modifiers: 2 - GPD; 3 - GST.

Fig. 1. The kinetics of water absorption of concrete

The increase in water pressure of concrete with additives is explained by the improvement (compaction) of the structure, colmatation of the pores and the hydrophobic effect. The studies of the pore structure of the modified cement stone found that the possibility of obtaining high-quality cement matrix. Capillary cracks proliferation is reduced and microporosity with pore sizes of $\approx 0.1$ micron develops due to the crushing of large pores.

To determine the sulfate resistance, mortar samples of $40 \times 40 \times 160 \mathrm{~mm}$ at the age of 28 days after weighing were placed in a 5\% aqueous solution of sodium sulfate to a depth of 5 $\mathrm{cm}$ and kept there for 6 months. Studies indicated that modified concrete composition had 1.8 times less intensity of weight gain and 2 times less height of efflorescence appearance in comparison with the control specimen. High sulfate resistance of the proposed concretes is explained by the suppression of the growth of salt crystals as a result of their amorphization, decrystallization, which significantly reduces the physical corrosion of the cement stone. hydrophobic concrete that has a dense structure. Forming corrosion products in the hydrophobic interporous space are modified, i.e., most part of the poorly soluble salts doesn't crystallize and passes into an amorphous state which in accordance with the studies $[7,9,10]$. This leads to a decrease in stresses in the pores of the concrete and naturally to a decrease in the destructive effect on the structural elements of the concrete. Thus, the development of sulfate corrosion in modified concrete is hampered by the hydrophobization of the capillary-porous structure, which impedes the penetration of corrosive waters into the concrete body, as well as by modifying the corrosion products under the action of the hydrophobic pore space of the cement stone.

It is commonly known that the frost resistance of concrete is one of the factors for the reliability of building products and structures. In particular frost resistance is a factor for their durability. The results of tests of concrete with hydrophobized complex modifiers for frost resistance according to the accelerated method are shown in Figure 2. 


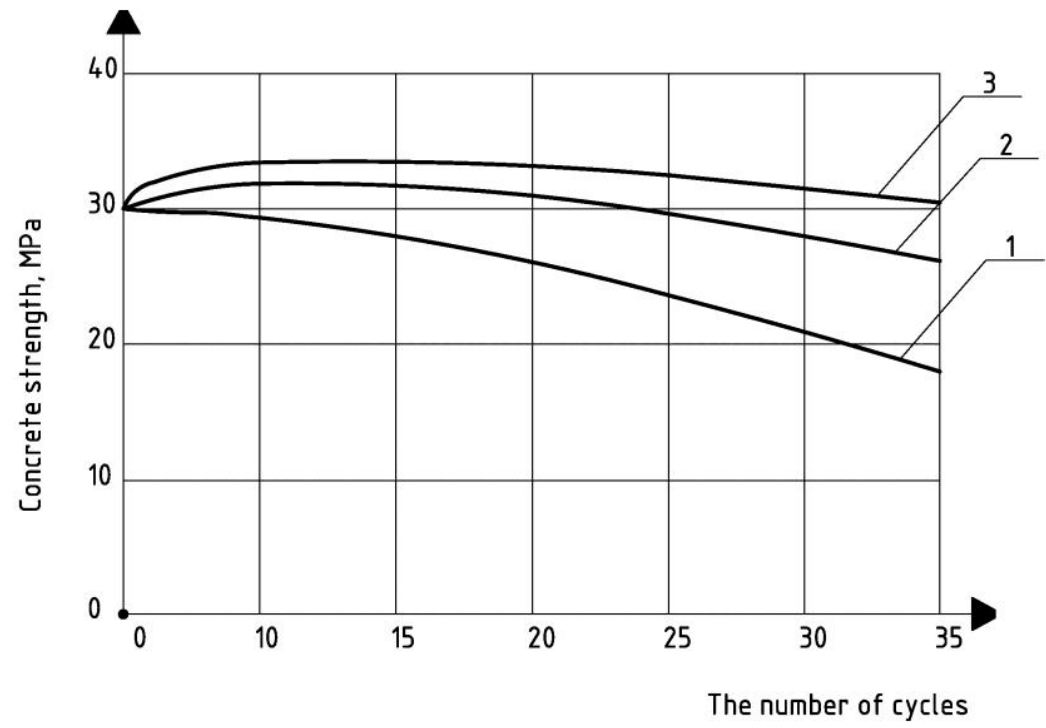

1 - composition without modifier ; with modifiers: 2 - GPD; 3 - GST.

Fig. 2. Effect of modifying additive on the strength of concrete at alternate freeze-thaw (the accelerated method)

Tests for alternate freeze-thaw of the investigated compositions showed that the strength decreases in modified concrete after 37 cycles in comparison with the control one after 12 test cycles. The proposed hydrophobic modifier reduces the loosening of the concrete structure. Amorphization of ice occurs as a result of modifying the processes of ice formation. When it is thawed, active melt water is formed in concrete. Then melt water flow rushes into the formed defects of the cement stone structure. As a result of hydration processes, modified tightly fused hydration products are formed on the exposed areas of the clinker pool. Hydration products "self-heal" defects in the structure of concrete, which determines the increased frost resistance of concrete. The results are consistent with the studies $[4,7,9-11]$.

It is found that the developed GTS type complex hydrophobic modifier improves the strength and deformative properties of concrete (Table 4).

Table 4. Physical and technical properties of the pressed mortar beam with hydrophobic binder with low water demand (GVNV-50C)

\begin{tabular}{|c|c|c|c|}
\hline \multirow{2}{*}{$\begin{array}{c}\text { Modifier, \% by } \\
\text { weight of binder }\end{array}$} & $\begin{array}{c}\text { Compressive strength, } \\
\mathrm{MPa}\end{array}$ & \multicolumn{2}{|c|}{ Stress-strain properties } \\
\cline { 3 - 4 } & 33,1 & $\begin{array}{c}\text { modulus of elasticity } \\
\mathrm{E} \cdot 10^{-3}, \mathrm{MPa}\end{array}$ & $\varepsilon_{\mathbf{y c}} 10^{-5}, \mathrm{~mm} / \mathrm{m}$ \\
\hline $\begin{array}{c}\text { without modifier } \\
\text { (control sample) }\end{array}$ & 37,2 & 34,5 & 40 \\
\hline GPD $0,6 \%$ & 39,1 & 34,8 & 38 \\
\hline GTS $0,6 \%$ & \multicolumn{3}{|c}{} \\
\hline
\end{tabular}

The results of table 4 show that the strength of concrete with modifiers increased by 12 $18 \%$ in comparison with the control sample. Also, hydrophobic modifiers help to reduce 
shrinkable deformations of concrete by $7.5 \%$ in comparison with plain composition and thereby prevent dangerous shrinkage crack proliferation.

\section{Conclusions}

Research results presented in this study indicate that the use of a hydrophobicizing modifier in cement systems based on industrial wastes, including technical lignosulfonates (LST) as a plasticizing ingredient, a hydrophobicizing ingredient - oil and fat tar and air-attractant agent - saponified wood resin (SWR) in cement systems is effective to improve the perfomance of concrete intended for irrigation and drainage construction.

\section{References}

1. A. Grishina, E. Korolev, PFSD-2015, (2015)

2. A. Grishina, E. Korolev, PFSD-2016, (2016)

3. L.A Suleymanova, V.S Lesovik, K.A. Kara, M.V. Malyukova, K.A. Suleymanov, Res. Jour. of App. Scien., 9, (2014)

4. Y.M. Bazhenov, E.M. Chernyshov, D.N. Korotkih, Build. Mater., 6, 3, (2014)

5. E.S. Argal, V.M. Korolev, K.P. Kudrin, V.A. Ashikhmen, Pow. Techn. And Engin., 337, 43, (2009)

6. Y.G. Barabanshchikov, K.V. Semenov, Pow. Techn. And Engin., 197, 41, (2007)

7. E.V Tkach, V.C. Semenov, S.A. Tkach, T.A.Rozovskaya, Proc. Engin. 24th Cep. XXIV R-S-P seminar - Theor. Foun. of Civ. Engin., TFoCE, 763, (2015)

8. N. Zhu, F. Jin, X. Kong, B. Wang, H. Wu, Constr. And Build. Mat., 1085, 188, (2018)

9. V.G. Batrakov, Modified concretes (Stroyizdat, Moscow, 1998)

10. C. Han, W. Shen, X. Ji, Z. Lv, X. Tang, Constr. And Build. Mat., 426, 187, (2018)

11. E.V. Tkach Comprehensive gidrofobizatsii modification of concrete (monogr.), (FGBOU VPO MGSU, Moscow, 2011) 